Occasional Publication No. 19 - British Society of Animal Science 1995

edited by T. L. J. Lawrence, F. J. Gordon and A. Carson

\title{
The effects of genetic merit on nutrient utilization in lactating dairy cows
}

\author{
D. C. Patterson, F. J. Gordon, C. S. Mayne, M. G. Porter and E. F. Unsworth \\ Agricultural Research Institute of Northern Ireland, Hillsborough, Co. Down BT26 6DR
}

\section{Introduction}

The United Kingdom dairy industry is entering a period of rapid increase in cow genetic merit (CGI90) through the use of Holstein breeding material from North America and Holland. The current study examined the effects of genetic merit on performance and nutrient utilization of lactating dairy cows.

\section{Material and methods}

Cows of high, medium and low genetic merit (CGI90 approx. 950, 650 and 550) were offered a diet with a forage (grass silage : dry matter (DM) $228 \mathrm{~g} / \mathrm{kg}$, digestible organic matter in the dry matter value $759 \mathrm{~g} / \mathrm{kg}$ ) to concentrate ratio of $36: 64$ on a DM basis from day 11 to day 160 of lactation. A total of 36 animals, 12 animals (10 cows plus two heifers) of each merit, were used in a radomized-block design. During each sequential 50 day period of the study

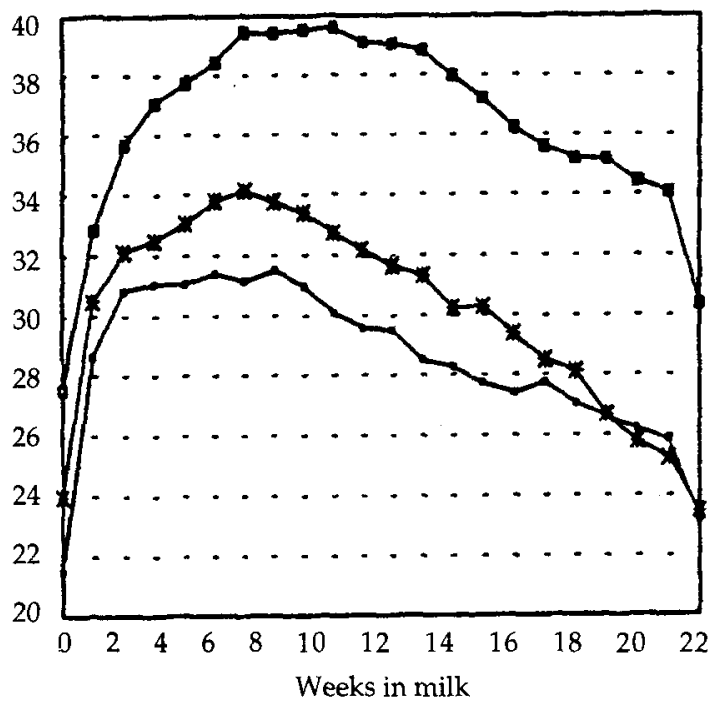

Figure 1 Milk yield by stage of lactation ( $\mathrm{kg} /$ day): - low-index, $-*$ - medium-index, - $\mathbf{-}$ - high-index. totals of four, six and six blocks of three animals from within the feeding study were subjected to diet apparent digestibility and nitrogen (N) balace measurements, followed by open-circuit calorimetry.

\section{Results and discussion}

Milk yield (Figure 1 and Table 1) was influenced by cow genetic merit and reached a mean peak of almost $40 \mathrm{~kg} /$ day for the high merit animals. The DM intake of the high merit cows was proportionately 0.06 higher than for the low merit animals, while intakes of the medium merit animals were intermediate. Intakes were similar when related to metabolic live weight. The small difference in DM intake across genetic merits, coupled with the much higher mean yields with the high merit animals, resulted in higher rates of live-weight depletion during the first 6 weeks of lactation (Figure 2). The

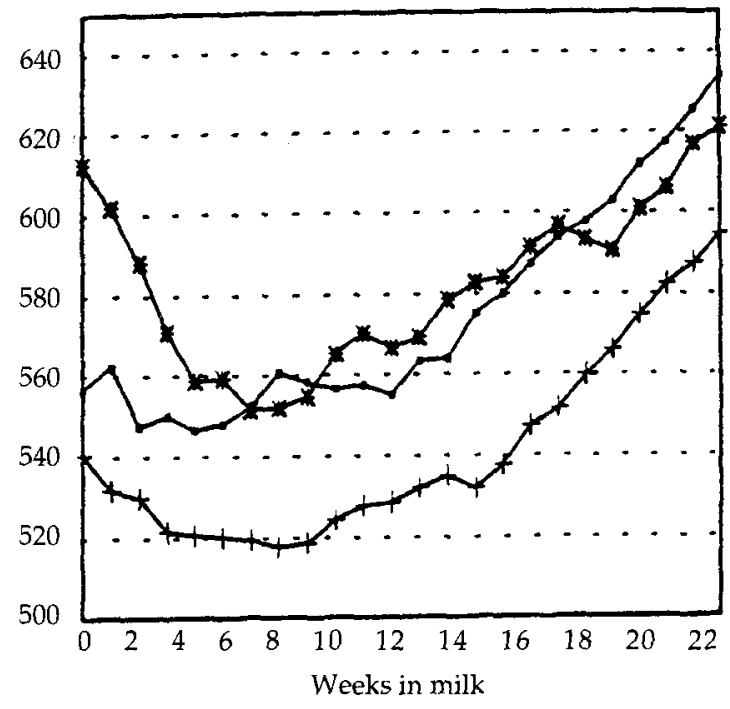

Figure 2 Live weight by stage of lactation $(\mathrm{kg})$ : - - low-index, -+- medium-index, - $*$-high-index. 
Table 1 The effects of cow genetic merit on animal performance and nutrient utilization

\begin{tabular}{|c|c|c|c|c|c|}
\hline & \multicolumn{3}{|c|}{ Cow genetic merit } & \multirow[b]{2}{*}{ s.e. } & \multirow[b]{2}{*}{ Significance } \\
\hline & High & Medium & Low & & \\
\hline Total dry matter intake ( $\mathrm{kg} /$ day) & $20 \cdot 2$ & $19 \cdot 4$ & 19.0 & 0.46 & \\
\hline Metabolizable energy (ME) intake (MJ/day) & 257 & 249 & 247 & $6 \cdot 1$ & \\
\hline $\mathrm{ME} /$ gross energyt $^{\circ}$ & 0.669 & 0.673 & $0 \cdot 683$ & 0.004 & \\
\hline Milk yield ( $\mathrm{kg} /$ day) & $37 \cdot 2^{a}$ & $30 \cdot 6^{\mathrm{b}}$ & $29 \cdot 0^{b}$ & 1.37 & $* * *$ \\
\hline Milk energy (MJ/day) & 117 & 99 & 90 & $3 \cdot 6$ & $* * *$ \\
\hline Butterfat yield ( $\mathrm{kg}$ / day) & $1 \cdot 40^{\mathrm{a}}$ & $1 \cdot 20^{\mathrm{b}}$ & $1.06^{\mathfrak{c}}$ & 0.05 & $* * *$ \\
\hline Protein yield (kg/day) & $1 \cdot 14^{a}$ & $0.99^{b}$ & $0.90^{\mathrm{b}}$ & 0.04 & $* * *$ \\
\hline Lactose yield (kg/day) & $1 \cdot 89^{\mathrm{a}}$ & $1 \cdot 55^{\mathrm{b}}$ & $1.49^{\mathrm{b}}$ & 0.07 & $* * *$ \\
\hline Initial live weight (kg) & $631^{\mathrm{a}}$ & $551^{\mathrm{b}}$ & $528^{\mathrm{b}}$ & $16 \cdot 7$ & $* * *$ \\
\hline Live-weight gain $(\mathrm{kg} /$ day $)$ & $-0.02^{a}$ & $0.34^{\mathrm{b}}$ & $0.53^{b}$ & 0.084 & $* * *$ \\
\hline Milk energy / ME intake & 0.46 & 0.40 & 0.36 & 0.012 & $* * *$ \\
\hline Milk N/N intake & 0.31 & 0.27 & 0.26 & $0 \cdot 010$ & ** \\
\hline$k_{l} \ddagger$ & 0.62 & 0.57 & 0.55 & 0.021 & \\
\hline
\end{tabular}

+ Determined using measurement of methane production.

$\ddagger$ Calculated using ARC (1980) data for energy content of body weight change.

higher merit animals also had a much lower rate of body reserve repletion during the mid-lactation period.

Metabolizable energy (ME) intake was highest with the high merit animals, but the differences in $\mathrm{ME}$ intake were not significant $(P>0.05)$. Milk energy output increased very considerably $(P<0.001)$ with increase in genetic merit and gross energetic efficiency, expressed as milk energy as a proportion of ME intake was highest with the high index cows. Milk $\mathrm{N} / \mathrm{N}$ intake also increased with increase in genetic merit. Values for $k_{l}$ for animals in the production study were estimated using assumed values for maintenance requirement (Agricultural Research Council (ARC), 1980), and energy contents of live-weight change (Agricultural and Food Research Council, 1990) and the ME intake and milk energy outputs obtained in the overall production study. The $k_{l}$ values were similar across the genetic merits.

\section{Conclusions}

1. Cow genetic merit had a considerable influence on the outputs of milk, milk components and milk energy with mean treatment yields of approximately $40 \mathrm{~kg} /$ day being obtained for the highest index animals in early lactation.

2. DM and energy intakes were only slightly increased with increasing genetic merit, therefore increasing genetic merit resulted in increased mobilization of body reserves.

3. Partial efficiency of ME use for milk production, $k_{l}$, was not significantly affected by genetic merit.

\section{References}

Agricultural and Food Research Council. 1990. Nutritive requirements of ruminant animals : energy. Technical Committee on Responses to Nutrients; report no. 5. Nutrition Abstracts and Reviews, Series B 60: 729-804.

Agricultural Research Council. 1980. The nutrient requirements of ruminant livestock. Commonwealth Agricultural Bureau, Slough. 